\title{
Expression of complement receptors and regulatory proteins on alveolar CD4+ lymphocytes from human immunodeficiency virus- 1 infected individuals
}

\author{
S.P. Aries*, B. Schaaf*, F. Hansen*, K. Weyrich*, \\ V. Kurowski*, R. Dennin**, K. Dalhoff*
}

Expression of complement receptors and regulatory proteins on alveolar CD4+ lymphocytes from human immunodeficiency virus-1 infected individuals. S.P. Aries, B. Schaaf, F. Hansen, K. Weyrich, V. Kurowski, R. Dennin, K. Dalhoff. (C)ERS Journals Ltd 1997. ABSTRACT: Several lines of evidence suggest a dysregulation of the complement system in human immunodeficiency virus-1 (HIV-1) infected patients. The aim of this study was to elucidate whether CD4+ alveolar lymphocytes from HIV-1 infected patients show a loss of complement regulatory proteins that would render these cells susceptible to antibody-dependent complement-mediated cytotoxicity.

We investigated the expression of complement regulatory (CD46, CD55, CD59) and complement receptor (CR1, CR2, CR3, CR4) proteins on alveolar cells by flow cytometry. Cells were obtained by bronchoalveolar lavage from $17 \mathrm{HIV}-1$ infected and 12 HIV-1 negative individuals. Expression of adhesion molecules (leucocyte functional associated antigen-1 (LFA-1), intercellular adhesion molecule-1 (ICAM1)) and CD30 were evaluated in patient subgroups. In addition, interleukin (IL)$1 \beta$, tumour necrosis factor alpha (TNF- $\alpha$ ), IL-4 and interferon gamma (IFN- $\gamma$ ) concentrations were measured in supernatants of alveolar cells.

We found a significantly reduced expression of CD46 and CD59 on CD4+ alveolar lymphocytes from HIV-1 infected individuals, whereas the expression of CR3, CR4, ICAM-1 and CD30 was increased. IL-1 $\beta$ and TNF- $\alpha$ concentration in supernatants of alveolar cells was augmented in HIV-1 infected patients, but did not correlate with the expression of surface molecules. IFN- $\gamma$ concentration was also increased and showed an inverse relationship to the surface expression of CD30 on CD4+.

Our data suggest that in human immunodeficiency virus-1 infection an increased level of activation is associated with a diminished expression of complement regulatory proteins on CD4+ alveolar lymphocytes. This phenomenon might contribute to the depletion of CD4+ lymphocytes and the local immunodeficiency in the pulmonary compartment.

Eur Respir J 1997; 10: 1736-1741.
*Dept Internal Medicine II and **Institute for Medical Microbiology, Medical University Lübeck, Germany.

Correspondence: S.P. Aries

Dept Internal Medicine II

Medical University Lübeck

Ratzeburger Allee 160

23538 Lübeck

Germany

Keywords: Bronchoalveolar lavage complement

human immunodeficiency virus-1

Received: December 101996

Accepted after revision May 101997

Presented in part at the 1996 congress of the European Respiratory Society. Supported by a grant from the Grimmke Foundation, Düsseldorf, Germany.
The hallmark of immunodeficiency in human immunodeficiency virus-1 (HIV-1) infection is the loss of CD4+ T-cells. A conclusive explanation for the depletion of CD4+ T-cells has not been found to date. Apart from direct viral cytopathogenicity of at least some syncytium inducing strains, a number of indirect mechanisms, such as apoptosis and antibody-dependent complementmediated cytotoxicity (ACC), have been proposed.

Normal human cells are protected from the lytic action of homologous complement by membrane proteins that regulate activation and deposition of complement proteins. The membrane proteins complement receptor 1 (CR1 or CD35) [1], membrane co-factor protein (MCP or CD46) [2] and decay accelerating factor (DAF or CD55) [3] induce the dissociation of the C3 convertases, thus preventing further activation of complement. In addition, CD35 and CD46 act as co-factors for C3b cleavage by the serum enzyme factor I $[1,2]$. The mem- brane inhibitor of reactive lysis (MIRL or CD59) [4] and the homologous restriction factor (HRF) are two membrane proteins that prevent the assembly of the membrane attack complex (C5b-9).

Recently we have shown that certain CD4+ lymphoid cell lines lacking the expression of complement regulatory proteins are susceptible to ACC when infected with HIV-1 [5]. The in vivo significance of this finding remains unclear.

Some reports suggest a decrease of the expression of complement regulatory proteins CD35, CD46, CD55 and CD59 [6-8] on peripheral blood cells from HIV-1 infected individuals. However, to date no comprehensive evaluation of the expression of complement receptors and regulatory proteins on tissue CD4+ T-cells has been performed. In HIV-1 infected patients, the lung is one of the most frequently affected organs. Infectious pulmonary complications contribute considerably to morbidity 
and mortality of acquired immune deficiency syndrome (AIDS) patients. It has been postulated that the local immunodeficiency in the lung is due to a progressive decline of the pulmonary cytolytic capacity that is at least partly attributable to a depletion of CD4+ alveolar lymphocytes (ALs) [9].

The aim of this study was, therefore, to elucidate whether CD4+ ALs from HIV-1 infected individuals have lost protection by complement regulatory proteins, since this increases the susceptility to ACC. As little is known about the regulation of the expression of complement regulatory and receptor proteins on T-cells, we examined the correlation between antigen expression, activation level as assessed by leucocyte functional associated antigen-1 (LFA-1) and intercellular adhesion molecule-1 (ICAM-1) expression, cytokine production of alveolar cells (ACs) and CD30 status. CD30 is expressed on T-cells that produce predominantly type $2 \mathrm{~T}$ helper (Th2) cytokines (i.e. interleukin (IL)-4, IL-10) rather than type $1 \mathrm{~T}$-helper (Th1) cytokines (i.e. IL-2, interferon gamma (IFN- $\gamma))$ [10].

\section{Patients and methods}

\section{Patients}

We investigated the expression of complement regulatory proteins and complement receptors on CD4+ ALs and alveolar macrophages (AMs) obtained from 17 HIV1 infected individuals (mean \pm SEM age $43 \pm 11 \mathrm{yrs}$; three female and 14 male; six smokers and 11 nonsmokers; one patient stage CDC I, three patients stage II and 13 patients stage III). The mean blood CD4 cell count was $134 \pm 133$ cells $\cdot \mu \mathrm{L}^{-1}$. All but two patients were on current antiretroviral therapy. For comparison, seven healthy volunteers (mean age $25 \pm 3$ yrs; all male; all nonsmokers) and five patients with suspected $(n=2)$ or proven $(n=3$; all stage T1, squamous cell carcinomas) peripheral malignancy of the lung (mean age 58 \pm 7 yrs; all male; all smokers) were evaluated in the same manner by bronchoalveolar lavage (BAL). In HIV-1 infected patients, BAL was performed for exclusion (10 cases) or confirmation of opportunistic infections (seven patients; Mycobacterium tuberculosis (one), Cryptococcus neoformans (one), Pneumocystis carinii (two), other bacterial infections (three)).

\section{Bronchoalveolar lavage}

BAL was performed with a fibrescope (B71T20D; Olympus, Hamburg, Germany) placed in a wedge position in the middle lobe. Six to eight $20 \mathrm{~mL}$ aliquots of sterile saline were instilled and immediately aspirated.

Differential cell counts were performed after two washes in sterile saline solution and staining with WrightGiemsa. BAL samples with more than $10 \%$ neutrophils were excluded.

\section{Flow cytometry (FACS)}

Four million cells were pre-incubated for $30 \mathrm{~min}$ with $20 \%$ bovine serum (Sigma, Deisenhofen, Germany) to block nonspecific binding. After centrifugation for 10 min at $400 \times \mathrm{g}$, cells were washed twice in phosphate buffered saline (PBS) solution. Cells were conveyed in suitably sized FACS tubes and $10 \mu \mathrm{L}$ antibody was added. After 30 min incubation and two washes with PBS, twocolour flow cytometry (FACScan, Becton-Dickinson, Heidelberg, Germany) was performed using the following monoclonal antibodies: 1) Fluorescein conjugated: anti-CD4 (RPA-T4; Dianova, Hamburg, Germany); 2) R-phycoerythrin conjugated: anti-LFA-1 (C174/38; Biotrend, Köln, Germany), anti-CR3 (C135/44; Biotrend), anti-CR4 (3.9; Sigma, Deisenhofen, Germany), anti-CR2 (MON-1112R; CellSystem, Remagen, Germany), antiCD30 (Ber-H2; Dako, Hamburg, Germany) and antiICAM-1 (C169/15.2; Biotrend); 3) Stained by secondary anti-mouse IgG R-phycoerythrin conjugated (27138, Dianova): anti-CR1 (J3D3; Dianova) and anti-CD46 (J4.48; Immunotech, Hamburg, Germany); and 4) Stained by secondary anti-mouse IgM R-phycoerythrin conjugated (SAM-2F; CellSystem): anti-CD55 (MON1155; CellSystem) and anti-CD59 (MON-1156; CellSystem)

Fluorescein and R-phycoerythrin conjugated monoclonal antibodies anti-IGG1 (Dianova) were used for negative controls.

In samples with secondary antibodies, anti-CD4 was added after two additional washing procedures; otherwise fluorescein and R-phycoerythrin conjugated antibodies were incubated together.

Instruments were calibrated with beads (Calibrite; Becton-Dickinson) and software (Autocomp; BectonDickinson). For gating and calculation, Lysis II software (Becton-Dickinson) was used. Gating for lymphocytes using forward/sideward scatter was facilitated by CD45/ CD14 (Becton-Dickinson) staining. A minimum of 10,000 events was acquired with at least $50 \mathrm{CD} 4+$ events in the lymphocyte gate, even in severely CD4-cell depleted patients. Log fluorescence intensity was displayed on a histogram in arbitrary fluorescence units. For the quantification of surface markers, linear median intensity emitted by bound monoclonal antibodies was divided by linear fluorescence median intensity of the corresponding isotype control. This calculation corrects for variation in cell autofluorescence between patients. The resulting ratio indicates the fold increase in average antigen density (relative linear mean fluorescence intensity (RLMFI)). A ratio of $\leq 1$ indicates no specific antigen expression.

\section{Cytokines}

For evaluation of cytokine secretion, AC concentration was adjusted to $10^{6} \mathrm{ACs} \cdot \mathrm{mL}^{-1}$ and cells were cultured unseparated in medium (M199; GIBCO, Eggenstein, Germany) supplemented with $5 \%$ foetal calf serum (PAA; Linz, Austria) at $37^{\circ} \mathrm{C}$ in a $5 \% \mathrm{CO}_{2}$ enriched humidified atmosphere for $24 \mathrm{~h}$. Using commercially available enzyme-linked immunosorbent assay (ELISA) kits, IL$1 \beta$ (PerSeptive Diagnostics, Cambridge, USA), tumour necrosis factor alpha (TNF- $\alpha$ ) (PerSeptive Diagnostics), IL-4 (Laboserv, Staufenberg, Germany) and interferon gamma (IFN- $\gamma$ ) (Laboserv) concentrations were measured in the supernatant. 


\section{Statistical analysis}

Nonparametric statistical analyses were performed throughout the study. The Mann-Whitney U-test was used for independent samples and correlations were made with the Spearman's rank correlation test. Values are expressed as mean \pm SEM. A p-value of less than 0.05 was considered significant.

\section{Results}

CR1 and CR2 expression on CD4+ ALs in HIV-1 negative and positive individuals was too low to be reliably detected $(1.12 \pm 0.21$ versus $1.19 \pm 0.26$ RLMFI and $1.00 \pm 0$ versus $1.00 \pm 0$ RLMFI, respectively). Compared to controls, CD4+ ALs from HIV-1 infected individuals showed an increased CR3 and CR4 expression on their surface $(15.4 \pm 9.10$ versus $4.88 \pm 5.29$ RLMFI $(\mathrm{p}<$ $0.005)$ and $12.38 \pm 12.66$ versus $1.52 \pm 1.41$ RLMFI, $(\mathrm{p}<$ 0.005 ), respectively) (fig. 1). In contrast, a decreased expression of CD46 and CD59 was detected on CD4+ ALs from HIV-1 infected individuals (12.57 \pm 11.05 versus $26.68 \pm 10.70$ RLMFI $(\mathrm{p}<0.005)$ and $2.23 \pm 0.97$ versus 5.83 \pm 4.24 RLMFI, respectively $(\mathrm{p}<0.005))$. CD55 was equally expressed on CD4+ ALs in both groups (1.27 \pm 0.35 versus $1.15 \pm 0.20 \mathrm{RLMFI}$ ) (fig. 2).

CD4+ ALs from HIV-1 infected individuals showed an increased expression of CD30 (2.19 \pm 1.07 versus 1.25 \pm 0.30 RLMFI; $\mathrm{p}<0.01$ ) (fig. 3).

In addition, we found an increased expression of two adhesion molecules that are commonly used as activation parameters on CD4+ ALs from HIV-1 infected individuals (LFA-1 44.27 \pm 22.86 versus $25.80 \pm 13.03$ RLMFI $(\mathrm{p}<0.05)$ and ICAM-1 7.74 \pm 3.13 versus $2.19 \pm$ 0.98 RLMFI $(\mathrm{p}<0.005))$ (fig. 3).

Besides a decreased expression of CD59 on AMs from HIV-1 infected patients $(\mathrm{p}<0.05)$, no significant differences in the expression of any of the above-mentioned epitopes could be detected on AMs (table 1).

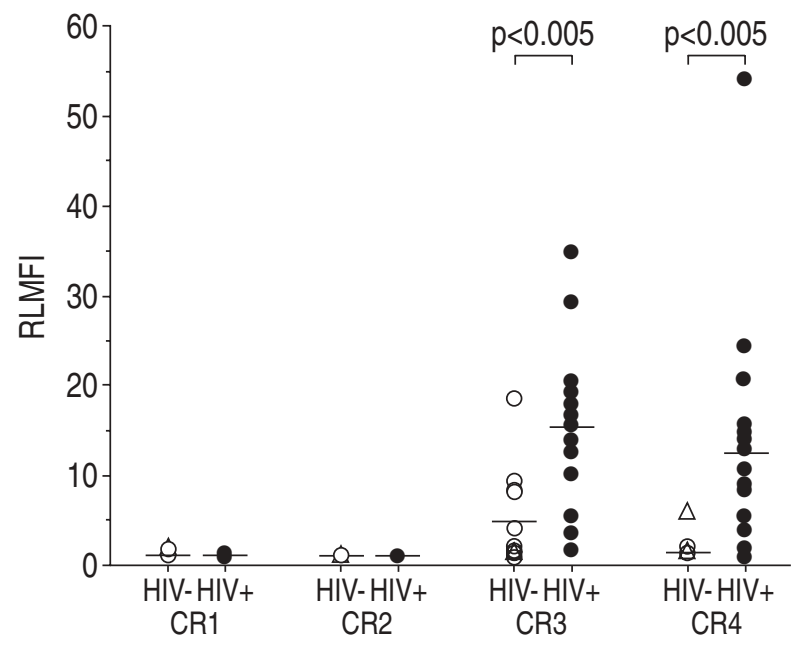

Fig. 1. - Expression (relative linear mean fluorescence intensity (RLMFI)) of complement receptors (CR)1 (CD35), CR2 (CD21), CR3 (CD11b) and CR4 (CD11c) on CD4+ alveolar lymphocytes (ALs) obtained from 17 human immunodeficiency virus (HIV)-1 infected $(\bullet)$ and $12 \mathrm{HIV}-1$ negative individuals (O: volunteers; $\Delta$ : patients). Horizontal bars represent the mean. + : positive; - : negative.

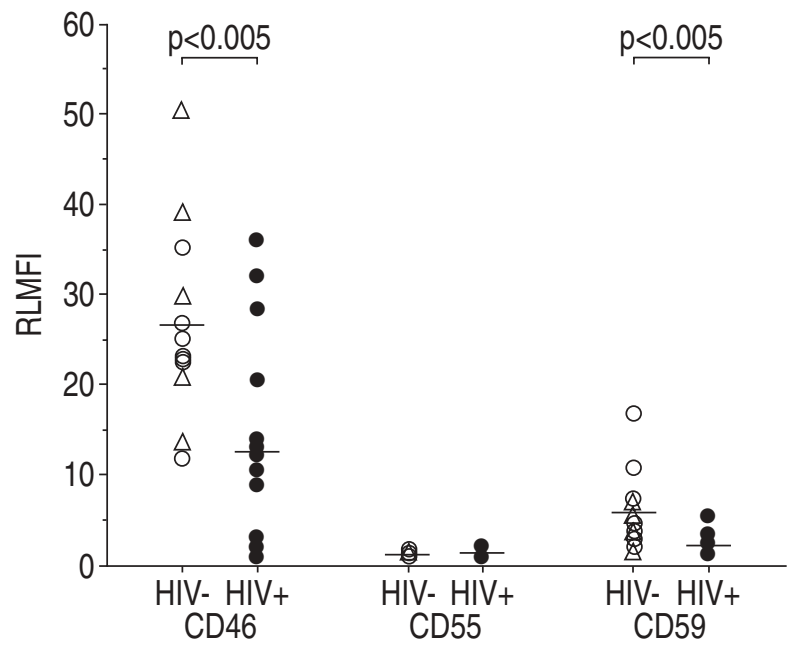

Fig. 2. - Expression (RLMFI) of CR proteins CD46, CD55 and CD59 on CD4+ ALs obtained from 17 HIV-1 infected $(\bullet)$ and 12 HIV-1 negative individuals ( $\mathrm{O}$ : volunteers; $\Delta$ : patients). Horizontal bars represent the mean. For definitions see legend to figure 1.

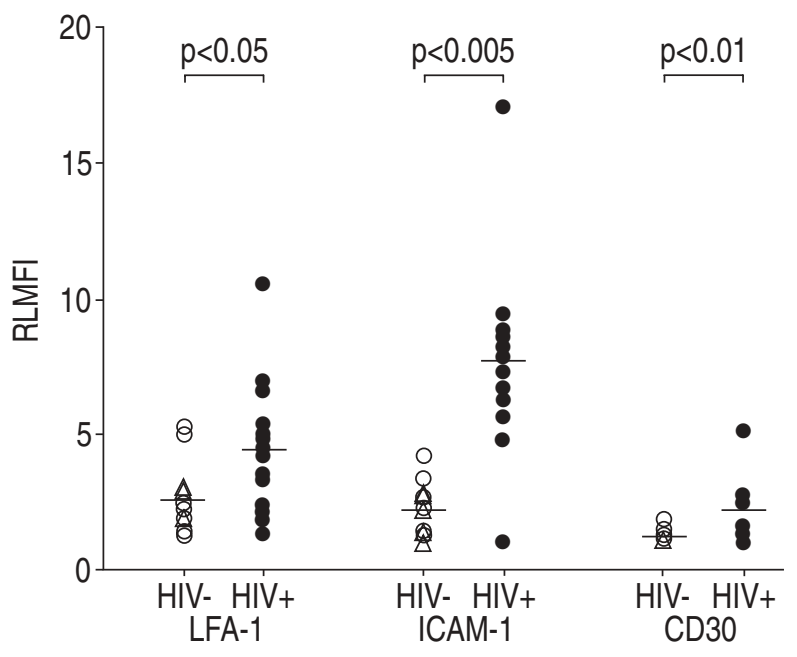

Fig. 3. - Expression (RLMFI) of leucocyte functional associated antigen (LFA-1) (CD11a; depicted values are divided by 10), intercellular adhesion molecule (ICAM-1) (CD54) and CD30 on CD4+ ALs obtained from 17 (resp. 14 (CD30)) HIV-1 infected (•) and 12 HIV-1 negative individuals ( $\mathrm{O}$ : volunteers; $\triangle$ : patients). Horizontal bars represent the mean. For definitions, see legend to figure 1.

Table 1. - Expression of complement receptors, complement regulatory proteins, leucocyte functional associated antigen (LFA-1) and intercellular adhesion molecule-1 (ICAM-1) on alveolar macrophages (AMs).

\begin{tabular}{lcc}
\hline & \multicolumn{2}{c}{ RLMFI } \\
\cline { 2 - 3 } & HIV+ & HIV- \\
\hline CR1 & $1.07 \pm 0.59$ & $1.17 \pm 0.09$ \\
CR2 & $1.13 \pm 0.29$ & $1.23 \pm 0.68$ \\
CR3 & $8.06 \pm 4.77$ & $6.20 \pm 3.41$ \\
CR4 & $5.93 \pm 3.46$ & $5.17 \pm 2.81$ \\
CD46 & $5.02 \pm 4.18$ & $4.55 \pm 2.44$ \\
CD55 & $1.46 \pm 1.08$ & $1.13 \pm 0.17$ \\
CD59 & $1.81 \pm 1.04$ & $3.10 \pm 2.08$ \\
LFA-1 & $5.73 \pm 4.74$ & $5.09 \pm 2.62$ \\
ICAM-1 & $2.46 \pm 0.88$ & $2.04 \pm 0.79$ \\
\hline
\end{tabular}

Values are presented as mean \pm SD. AMs were obtained from $17 \mathrm{HIV}+$ and $12 \mathrm{HIV}$ - subjects (seven volunteers, five patients), RLMFI: relative linear mean fluorescence intensity; HIV: human immunodeficiency virus; + : positive; - : negative; CR: complement receptor; $\mathrm{CD}$ : complementary regulatory protein. 
The loss of CD46 and CD59 was inversely related to an increased expression of activation markers (LFA-1/ CD59: $r=-0.49, p<0.005$; ICAM-1/CD46: $r=-0.53, p<0.005$; ICAM-1/CD59: $r=-0.55, \mathrm{p}<0.005)$ and the proposed Th2 marker CD30 (CD30/CD46 r=-0.62, $\mathrm{p}<0.005$; CD30/ CD59 r=-0.61, p<0.005) (fig. 4).

The concentration of IL-1 $\beta\left(34.44 \pm 65.96 \mathrm{pg} \cdot \mathrm{mL}^{-1} \cdot 10^{6}\right.$ cells $\left.{ }^{-1}\right)$ and TNF- $\alpha\left(411.00 \pm 401.29 \mathrm{pg} \cdot \mathrm{mL}^{-1} \cdot 10^{6}\right.$ cells $\left.^{-1}\right)$ in $\mathrm{AC}$ supernatants from HIV-1 infected individuals was augmented but showed no correlation to the surface expression (RLMFI) of the tested antigens on ALs or AMs.

IFN- $\gamma$ concentration was increased in supernatants of ACs from HIV-1 infected individuals (29.23 \pm 28.99 versus $10.90 \pm 7.58 \mathrm{pg} \cdot \mathrm{mL}^{-1} \cdot 10^{6}$ cells $^{-1}, \mathrm{p}<0.05$ ) (fig. 5) and was inversely related to the surface expression CD30 on CD4+ AL within the HIV-1 infected group $(n=14$, $\mathrm{r}=-0.79, \mathrm{p}<0.005$ ) (fig. 6).

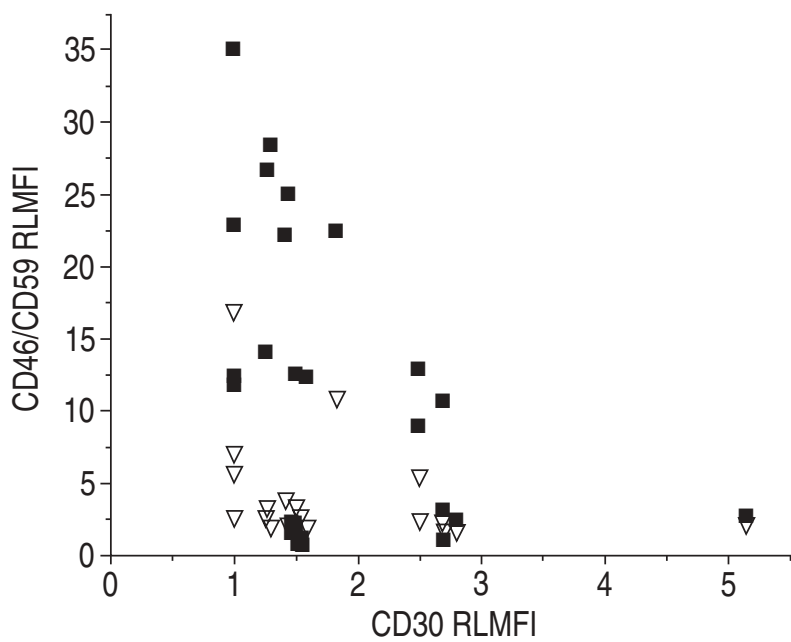

Fig. 4. - Correlation between the expression (RLMFI) of CD30 and CR proteins $(C D 46(\square) r=-0.62, p<0.005 ; \operatorname{CD} 59(\nabla) r=-0.61, p<0.005)$ on CD4+ ALs obtained from 14 HIV-1 infected and seven HIV-1 negative individuals (all volunteers). For definitions see legend to figure 1 .

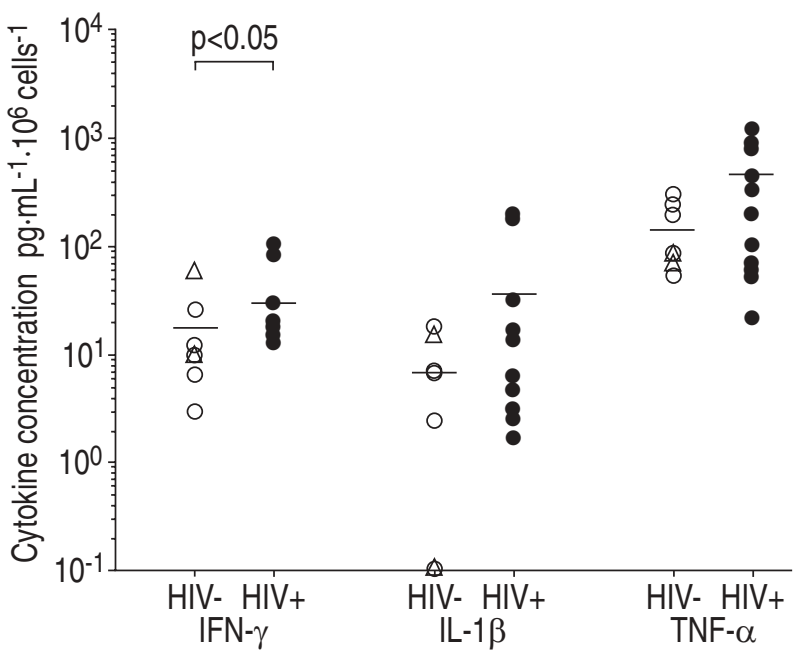

Fig. 5. - Cytokine concentrations of interferon gamma (IFN- $\gamma$ ), interleukin- $1 \beta$ (IL-1 $\beta$ ) and tumour necrosis factor- $\alpha$ (TNF- $\alpha$ ) in supernatants of unseparated alveolar cells (ACs) obtained from 13 (IL-1 $\beta$ and TNF- $\alpha$ ) or 14 (IFN- $\gamma$ ) HIV-1 infected $(\bullet)$ and eight HIV-1 negative individuals ( $\mathrm{O}$ : volunteers; $\Delta$ : patients). Horizontal bars represent the mean. For definitions see legend to figure 1.

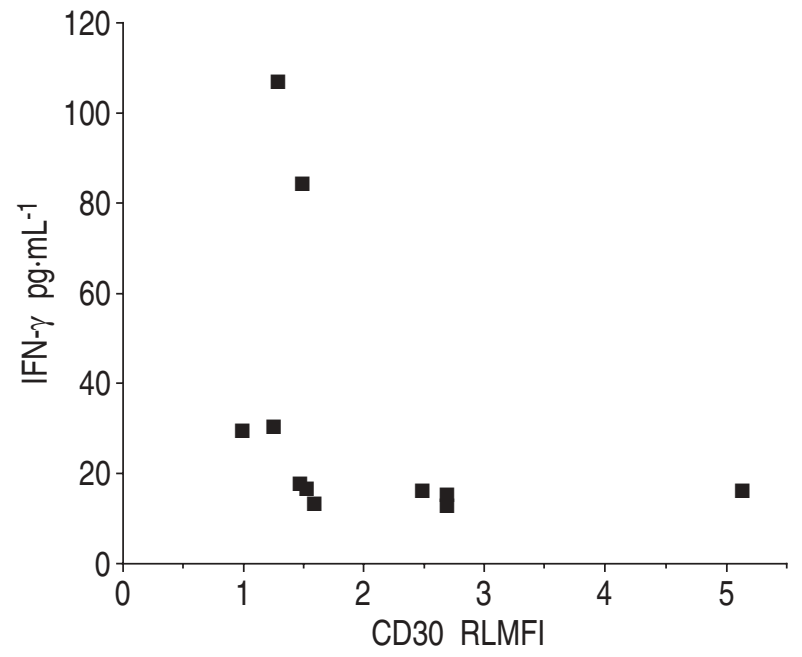

Fig. 6. - Correlation between the expression (RLMFI) of CD30 and concentrations of interferon gamma (IFN- $\gamma)(\mathrm{r}=-0.79, \mathrm{p}<0.005)$ in supernatants of unseparated alveolar cells (ACs) obtained from 14 HIV-1 infected subjects. For definitions see legend to figure 1.

Employing an assay with a lower limit of detection of $7.8 \mathrm{pg} \cdot \mathrm{mL}^{-1}$ we failed to detect the Th2 cytokine IL4 in supernatants of AC.

Pulmonary infection did not have any demonstrable effect on levels of expression of any of the investigated surface molecules in HIV-1 infected patients (data not shown).

\section{Discussion}

The broad spectrum of pulmonary diseases seen in HIV-1 infected patients is thought to be a consequence of a virus-induced local immunodeficiency, which is characterized by a severe depletion of CD4+ ALs [9]. Our study was therefore conducted to clarify whether, in HIV-1 infection, expression of complement regulatory and receptor proteins on ACs is altered and contributes to the decline of pulmonary cellular immunity. The main finding of the present study was a significant downregulation of the expression of the complement regulatory proteins $\mathrm{CD} 46$ and $\mathrm{CD} 59$ on $\mathrm{CD} 4+\mathrm{AL}$ in HIV-1 infected individuals.

A decreased expression of complement regulatory proteins has been demonstrated on the surface of peripheral blood T-cells from HIV infected patients [8, 11]. In contrast to these reports we found no reduction of CD55 on ALs, which might be due to a low level of expression in HIV-1 negative controls. Unlike previous investigators [8], we detected a reduced expression of complement regulatory proteins, primarily on CD4+ ALs with only a trend toward reduction in the CD4subset (data not shown). These discrepancies may be attributable to the different investigational sites.

A dysregulation of the expression of complement controlling proteins is known to be of pathogenetic importance in other viral infections, such as measles, where a viral tropism for CD46 on lymphocytes might account for the observed lymphopenia [12]. In HIV-1 infection a loss of complement regulatory proteins is known to facilitate ACC of infected CD4+ T-cells [5] and might render them susceptible for apoptosis [13, 
14], as recently described for blood polymorphonuclear leucocytes [15].

The following mechanisms may contribute to the downregulation of membrane-bound complement regulatory proteins in HIV-1 infection.

\section{Cytokine-mediated regulation}

In human vascular endothelial cells the expression of CD46, CD55 and CD59 is regulated by cytokines [16]. An increased production of TNF- $\alpha$ and IL- $1 \beta$ by blood monocytes [17] and AMs [9, 18] in AIDS patients has been reported. However, we could not establish a correlation between CD46 and CD59 expressed on CD4+ ALs and TNF- $\alpha$ and IL-1 $\beta$ levels. This may be due to the influence of other cytokines, which are known to play a role in the pulmonary immune response to HIV1 infection. T-cell derived IL-2, for example, has been shown to reconstitute expression of complement regulatory proteins on CD4+ T-cells from HIV-1 infected patients when cultured in vitro [19], which might be one of the mechanisms that account for the rise in CD4+ $\mathrm{T}$-cell counts in some patients treated with intermittent infusions of IL-2 [20].

\section{Virus-induced effect}

In productively infected CD4+ ALs, HIV-1 itself might cause a reduced expression of complement regulatory proteins. This is due to an incorporation of CD55 and CD59 into newly produced virions protecting them from complement-mediated destruction [21]. However, presuming that the viral load in lung tissue parallels the plasma levels as has been shown for lymph nodes [22], we were not able to establish a correlation between the available plasma HIV-1 ribonucleic acid (RNA) levels $(n=13)$ and the antigen expression on CD4+ AL (data not shown).

\section{Activation-induced effect}

We found evidence to assume that immune activation is associated with decreased expression of complement regulatory proteins on the surface of CD4+ ALs. The increased expression of LFA-1 and ICAM-1 on CD4+ ALs might be of functional importance since cell adhesion and intercellular communication are essential mechanisms of cellular immunity.

\section{Th1/Th2 shift}

The expression of CD30 was inversely related to the decline of CD46 and CD59 expression. CD30 is a member of the tumour necrosis factor/nerve growth factor receptor superfamily [23]. CD30 is not exclusively [24], but preferentially [10], expressed on activated CD4+ Tcell clones that produce Th2 cytokines. This finding is supported by the negative correlation we found within the HIV-1 infected cohort between the expression of CD30 on CD4+ ALs and the concentrations of IFN- $\gamma$ in supernatants of ACs. Unfortunately we were not able to detect IL-4 in supernatants of ACs. This finding is consistent with previous studies reporting high levels of IFN- $\gamma$ and no detectable IL-4 in supernatants of ALs obtained from HIV-1 infected individuals [25]. A relative predominance of Th2 cells in HIV-1 infection as a consequence of apoptosis and anergy of Th1 cells has recently been postulated [26].

In conclusion, our data indicate that the dysregulation of the expression of cell-bound components of the complement network on CD4+ alveolar lymphocytes from human immunodeficiency virus-1 infected individuals is related to an increased activation of the immune system and a shift in the type 1/type 2 T-helper cell profile. Future studies have to address the functional relevance of these findings for the CD4+ T-cell depletion taking place in the pulmonary compartment.

Acknowledgements: The authors thank M. Losch and B. Weitzner for excellent technical assistance and A. Remppis for helpful comments on the text.

\section{References}

1. Panburn MK. Differences between the binding sites of the complement regulatory proteins DAF, CR1 and factor H on C3 convertases. J Immunol 1986; 136: 2216-2221.

2. Kojima A, Iwata K, Seya $\mathrm{T}$, et al. Membrane cofactor protein (CD46) protects cells predominantely from alternative complement pathway-mediated $\mathrm{C} 3$-fragment deposition and cytolysis. J Immunol 1993; 151: 15191527.

3. Nicholson-Weller A, Burge J, Fearon DT, Weller PF, Austen KF. Isolation of a human erythrocyte membrane glycoprotein with decay-accelerating activity for C3 convertases of the complement system. J Immunol 1982; 129: 1519-1527.

4. Okada N, Harada T, Fujita T, Okada H. A novel membrane glycoprotein capable of inhibiting membrane attack by homologous complement. Int Immunol 1989; 1: 205208.

5. Schmitz J, Zimmer JP, Kluxen B, et al. Antibodydependent complement mediated cytotoxicity in sera from patients with HIV-1 infection is controlled by CD55 and CD59. J Clin Invest 1995; 96: 1520-1526.

6. Cohen JH, Geffriaud C, Caudwell V, Kazatchkine MD. Genetic analysis of CR1 (the C3b complement receptor, CD35) expression on erythrocytes of HIV-infected individuals. AIDS 1989; 3: 397-399.

7. Jarvis JN, Taylor H, Long PM, Gutta PV, Pousak T, Fine N. Diminished expression of cell-surface complement regulatory proteins in HIV-infected children and with HIV infection of peripheral blood mononuclear cells in vitro. J Acquir Immune Defic Syndr Hum Retrovirol 1995; 9: 249-256.

8. Weiss L, Okada N, Haeffner Cavaillon N, et al. Decreased expression of the membrane inhibitor of complementmediated cytolysis CD59 on T-lymphocytes of HIV infected patients. AIDS 1992; 6: 379-385.

9. Agostini C, Trentin L, Zambello R, Semenzato G. HIV1 and the lung. Am Rev Respir Dis 1993; 147: 1038-1049.

10. Mosmann TR, Subash S. The expanding universe of T-cell subsets: Th1, Th2 and more. Immunol Today 1996; 17: 138-146. 
11. Lederman MM, Purvis SF, Walter E, Carey JT, Medof M. Heightened complement sensitivity of acquired immunodeficiency syndrome lymphocytes related to diminished expression of decay accelerating factor. Proc Natl Acad Sci USA 1989; 86: 4205-4209.

12. Seya T. CD46, a complement regulatory protein-measles virus receptor, and its relation to hematological disorders. Inter J Hematol 1996; 64: 101-109.

13. Ameisen JC, Estaquier J, Idziorek T, De Bels F. The relevance of apoptosis to AIDS pathogenesis. Trends Cell Biol 1995; 5: 27-31.

14. Aries SP, Schaaf B, Müller C, Dennin RH, Dalhoff K. Fas (CD95) expression on CD4+ T-cells from HIV infected patients increases with disease progression. $J \mathrm{Mol}$ Med 1995; 73: 591-593.

15. Jones J, Morgan BP. Apoptosis is associated with reduced expression of complement regulatory molecules, adhesion molecules and other receptors on polymorphonuclear leucocytes: functional relevance and role in inflammation. Immunology 1995; 86: 651-660.

16. Moutabarrik A, Nakanishi I, Namiki M, et al. Cytokinemediated regulation of the surface expression of complement regulatory proteins CD46 (MCP), CD55 (DAF) and CD59 on human vascular endothelial cells. Lymph Cyt Res 1993; 17: 167-172.

17. Roux-Lombard P, Modoux C, Cruchaud A, Dayer JM. Purified blood monocytes from HIV-1 infected patients produce high levels of TNF- $\alpha$ and IL-1. Clin Immunol Immunopathol 1989; 50: 374-384.

18. Cox RA, Anders GT, Capelli PJ, Johnson JE, Blanton HM, Seaworth BJ. Production of TNF- $\alpha$ and IL-1 by AM from HIV-1 infected persons. AIDS Res Hum Retroviruses 1990; 6: 431-441.
19. van Lunzen J, Schmitz J, Dengler K, Kuhlmann C, Schmitz H, Dietrich M. Investigations on autologous T-cells for adoptive immunotherapy of AIDS. Adv Exp Med Biol 1995; 374: 57-70.

20. Kovacs JA, Vogel S, Albert JM, et al. Controlled trial of interleukin-2 infusions in patients infected with the human immunodeficiency virus. N Engl J Med 1996; 335: 1350-1356.

21. Saifuddin M, Parker CJ, Peeples ME, et al. Role of virion-associated glycosylphosphatidylinositol-linked proteins CD55 and CD59 in complement resistance of cell line derived and primary isolates of HIV-1. J Exp Med 1995; 182: 501-509.

22. Lafeuillade A, Poggi C, Profizi N, Tamalet C, Costes O. Human immunodeficiency virus type 1 kinetics in lymph nodes compared with plasma. J Infect Dis 1996; 174: 404-407.

23. Schwab U, Stein H, Gerdes J, Lemke H, Kirchner HH, Schadt M. Production of a monoclonal antibody specific for Hodgkin and Sternberg-Reed cells of Hodgkin's disease and a subset of normal lymphoid cells. Nature 1982; 299: 65.

24. Hamann D, Hilkens CMU, Grogan JL, et al. CD30 expression does not discriminate between human Th1and Th2- type T-cells. J Immunol 1996; 156: 1387-1391.

25. Spain BA, Soliman DM, Sidner RA, Twigg HL. Enhanced proliferation and IL-2 secretion by lung lymphocytes from HIV-infected subjects. Am J Physiol 1995; 269: L498-L506.

26. Meyaard L, Schuitemaker H, Miedema F. T-cell dysfunction in HIV infection: anergy due to defective antigen-presenting cell function? Immunol Today 1993; 14: 161-165. 